\title{
Over-Savings and Hyperbolic Discounting ${ }^{1}$
}

\author{
François Salanié \\ Nicolas Treich ${ }^{2}$ \\ Université de Toulouse (LERNA, INRA), France
}

July 5,2004

${ }^{1}$ We thank Yann Bramoullé, Isabelle Brocas, Christian Gollier, Thomas Mariotti and Bernard Salanié for useful discussions. We also thank two anonymous referees together with the Editor for their insightful and stimulating comments. The usual disclaimer applies.

${ }^{2}$ Both authors at Lerna Inra, Manufacture des Tabacs Bat F, 21 Allées de Brienne, 31042 Toulouse, France. Corresponding author's email: ntreich@toulouse.inra.fr 


\begin{abstract}
Hyperbolic discounting models are widely seen as implying that consumers do not save enough, in accordance with the observed low rates of savings of some households. This paper qualifies this statement by showing that hyperbolic consumers may 'oversave' in the short run. The result extends to uncertainty on future income and does not depend on whether preferences are present-biased or future-biased. A generalized comparative statics analysis of self-control is introduced, and its relationship to the analysis of uncertainty on future discount rates is emphasized.
\end{abstract}

Key-words: Self-control, Savings, Time-inconsistency, Discounting, Uncertainty.

JEL: D91, E21 


\section{Introduction}

It is often suggested that consumers' lack of self-control may explain undersavings patterns observed in western societies. This suggestion has found recent support in the hyperbolic discounting literature. Quasi-hyperbolic preferences in each period $t$ can be written as

$$
u\left(c_{t}\right)+\beta \sum_{i=1}^{T-t} \delta^{i} u\left(c_{t+i}\right),
$$

where the parameter $\beta \leq 1$ represents the 'bias for the present'. Various papers have shown that hyperbolic consumers (or $\beta<1$ ) save less than exponential (or $\beta=1$ ) consumers (Laibson, 1997, 1998, Harris and Laibson, 2001, Angeletos et al., 2001, Diamond and Koszegi, 2003). This literature thus predicts that the lack of self-control induced by hyperbolic discounting leads to undersavings. ${ }^{1}$

Notwithstanding the merits of the hyperbolic discounting literature to explain a wide range of empirical anomalies, the present paper qualifies this prediction. A crucial starting point is to recognize that comparing exponential and hyperbolic consumers is not an appropriate comparative statics

\footnotetext{
${ }^{1}$ This prediction dates back to the early literature on hyberbolic discounting. Phelps and Pollack (1968) showed that time-inconsistency must yield undersaving, in the sense that the agent without self-control would be better off at any period if he could save a bit more at all periods. This result relies on the fact that a time-inconsistent agent cannot commit to a consumption path at the beginning of the game he plays with future "selves". For a much larger class of preferences, Goldman (1979) proved a similar result: all selves would be better-off if self-1 saved more and transferred this extra-savings to a well-chosen future self. However, as Goldman recognized, "( $t$ )his phenomenon of over-consumption, as described above, does not preclude the existence of other Pareto superior solutions in which the first generation's consumption is increased" (Goldman, 1979, p.624).
} 
analysis to isolate the effect of self-control. Indeed, within a model with quasi-hyperbolic preferences, the parameter $\beta$ plays two roles. First, it indicates whether there is a self-control problem $(\beta<1)$ or not $(\beta=1)$. Second, it modifies the whole sequence of discount factors. A lower $\beta$ reduces discount factors for all subsequent periods. It is thus not surprising that reducing $\beta$ has been found to reduce savings.

In this paper, we instead propose to measure self-control as the ability to commit to a future consumption path. Consequently we argue that the right comparison should be performed between a consumer with commitment power and a consumer without it. In a simple three-period model, we show that the effect of self-control on savings critically depends on the curvature of the consumer's instantaneous utility function. Besides, under standard assumptions on this curvature, less self-control should lead to oversaving instead of undersaving. ${ }^{2}$ Furthermore, the effect of more or less self-control does not depend on whether the agent's preferences display a "bias for the present" or not.

We also generalize our analysis to any model in which an agent must sequentially take two decisions. Within such a general model, we show that the effect of more self-control on the first-period decision is qualitatively

\footnotetext{
${ }^{2}$ Pollack (1968) and more recently Barro (1999) perform the same comparison and notice that the degree of self-control has no effect on savings, when the instantaneous utility function is logarithmic. Indeed our results show that the logarithmic case is a knife-edge case. O'Donoghue and Rabin (1999a, 1999b) also proceed to this comparison in investment decision models and principal-agent models. Here we focus on a pure consumption model, with general utility functions.
} 
similar to the effect of introducing uncertainty on future discount factors. ${ }^{3}$ This allows us to provide an interpretation of our results in terms of an income and a substitution effect, exactly as done in the precautionary savings literature (Drèze and Modigliani, 1972).

In contrast to the hyperbolic discounting approach, Gul and Pesendorfer (2001, 2004) rely on an axiomatic basis to define the notions of self-control and temptation. Their representation theorems show that a decision-maker may experience costs associated to self-control. The agent chooses a different consumption in period 2 depending on whether decision takes place in period 1 or 2 . In the hyperbolic discounting approach, this is because preferences change over time; ex-ante commitment permits to constrain the future self. By contrast Gul and Pesendorfer postulate that temptation and costly self-control are experienced only in period 2. Hence commitment is valued because it reduces temptation during the period 2's decision process. What is the effect of self-control on early savings in the Gul and Pesendorfer's framework? Gul and Pesendorfer (2004, Proposition 2) show that in a stationary infinite-horizon equilibrium an agent with more costly self-control consumes less. In contrast, in a two-period model, an agent with a temptation utility would reduce his savings in period 1 (Gul and Pesendorfer, 2002). ${ }^{4}$

\footnotetext{
${ }^{3}$ This relates to an emerging literature on uncertain discount rates. Sozou (1998) used uncertainty on future discount rates to show how hyperbolic discounting preferences may emerge from otherwise standard preferences. Dasgupta and Maskin (2002) extends Sozou's model to introduce both uncertainty on the timing of the rewards and a waiting cost.

${ }^{4}$ In short, the consumer maximizes $u\left(c_{1}\right)+v\left(c_{1}\right)-v(w)+\delta u\left(w-c_{1}\right)$ where $v$ is the temptation utility, $w$ is the available income and $v(w)-v\left(c_{1}\right)$ is interpreted as the cost of exercising self-control. When $v=0$, self-control has no cost. When $v$ is increasing,
} 
This raises the question of the effect of self-control in a three-period model similar to that we analyze in this paper. In fact, one can easily show that self-control leads to under-savings provided the temptation utility function is convex. ${ }^{5}$ This result stands in contrast to the over-savings pattern induced by hyperbolic discounting that we emphasize in this paper.

\section{The Model}

The interplay between savings and self-control has been analyzed for a long time (Strotz, 1956), using the following framework. An agent chooses a consumption plan for present and future periods given an intertemporal budget constraint. However his preferences may change over time. Formally, the marginal rate of substitution between consumptions in two given future periods depends on the period at which it is computed. To see that, let us simply consider a three-period hyperbolic discounting model. In period 1 preferences are

$$
u\left(c_{1}\right)+\beta \delta u\left(c_{2}\right)+\beta \delta^{2} u\left(c_{3}\right),
$$

while in period 2 preferences are written as

$$
u\left(c_{2}\right)+\beta \delta u\left(c_{3}\right)
$$

The discount factor between period 3 and period 2 is $\delta$ if it is computed at period 1 and $\beta \delta$ if it is computed at period 2. Thus the consumer is

consumption increases due to the term $v^{\prime}\left(c_{1}\right)$.

${ }^{5}$ Proof available from the authors upon request. 
dynamically inconsistent as soon as $\beta$ differs from 1 . When $\beta=1$, we are back to the case of a dynamically consistent consumer, with exponential discounting.

One may now distinguish two types of consumers. The sophisticated consumer chooses $c_{1}$ to maximize (1), knowing that in period 2 the consumption levels $c_{2}$ and $c_{3}$ will be chosen by his future self with preferences given by (2). Hence the sophisticate has no commitment power. The literature usually compares the sophisticate's behavior to the behavior of the exponential consumer with $\beta=1$. Our point here is that changing the value of $\beta$ not only changes the degree of self-control, but also the whole structure of discount factors; this renders the comparison irrelevant.

Instead we propose to compare the sophisticate's behavior to the behavior of an agent with the same preferences as in (1), and who can commit at period 1 to his whole consumption path $\left(c_{1}, c_{2}, c_{3}\right)$. In this sense, we isolate the pure effect of self-control. Notice that this agent also chooses $c_{1}$ in period 1 exactly as if he ignored the self-control problem characterized in (2). As it is customary in the literature (see, e.g., O'Donoghue and Rabin, 1999a), we shall therefore call him the naive consumer.

To perform the comparison between the naive and the sophisticate consumer, it is actually useful to introduce a slightly more general model. Pref- 
erences at the beginning of period 1 are given by

$$
u_{1}\left(c_{1}\right)+u_{2}\left(c_{2}\right)+\mu u_{3}\left(c_{3}\right) \text {, }
$$

where $u_{1}, u_{2}$ and $u_{3}$ are assumed to be increasing, strictly concave and three times differentiable. At the beginning of period 2, preferences change and become

$$
u_{2}\left(c_{2}\right)+\lambda u_{3}\left(c_{3}\right)
$$

so that these preferences match period 1's preferences if and only if $\lambda=\mu$. Present-biased (resp. future-biased) preferences are characterized by $\lambda<\mu$ $($ resp. $\lambda>\mu)$.

Observe that the hyperbolic discounting model $(1,2)$ may be obtained from $(3,4)$ by choosing

$$
u_{3}=u_{2}=\beta \delta u \quad u_{1}=u
$$

and

$$
\lambda=\beta \delta \quad \mu=\delta .
$$

In the following, we shall vary $\lambda$, keeping $\mu$ constant; this exactly amounts to vary $\beta$ in (2), keeping constant the weights in (1). We thus isolate the self-control effect of $\beta$ from its discounting effect.

Let us now introduce the budget constraint as

$$
w \geq R^{2} c_{1}+R c_{2}+c_{3},
$$


where $w$ is the future value of the flow of revenues and $R$ is one plus the risk-free rate. In this economy, the consumption levels chosen by the naive are simply characterized by

$$
u_{1}^{\prime}\left(c_{1}\right)=R u_{2}^{\prime}\left(c_{2}\right)=R^{2} \mu u_{3}^{\prime}\left(c_{3}\right),
$$

together with a binding budget constraint. On the other hand, the sophisticate consumer anticipates that consumption in period 2 will be chosen to maximize (4). The unique solution $c_{2}\left(c_{1}, \lambda\right)$ is characterized by

$$
u_{2}^{\prime}\left(c_{2}\left(c_{1}, \lambda\right)\right)=\lambda R u_{3}^{\prime}\left(w-R^{2} c_{1}-R c_{2}\left(c_{1}, \lambda\right)\right) .
$$

As a result, the sophisticate consumer plays a Stackelberg game with his period 2 self, and his optimal level of consumption in period 1 solves ${ }^{6}$

$$
\max _{c_{1}} u_{1}\left(c_{1}\right)+u_{2}\left(c_{2}\left(c_{1}, \lambda\right)\right)+\mu u_{3}\left(w-R^{2} c_{1}-R c_{2}\left(c_{1}, \lambda\right)\right)
$$

Notice that the naive agent in fact solves the same program, but with $\lambda=$ $\mu$. Therefore comparing the sophisticate and naive's first period consumption reduces to a comparative statics exercise with respect to $\lambda$ : how does the solution to program (7) vary when $\lambda$ varies?

\section{The Main Result}

To answer this question, we use the monotone comparative statics approach (Milgrom and Shannon, 1994). It is direct that a sufficient condition for $c_{1}$

\footnotetext{
${ }^{6}$ Existence of a solution is proven under weak conditions in Goldman (1980) in a general time-inconsistent preferences framework. Here, the conditions reduce to assuming that consumption is bounded from below.
} 
to increase in $\lambda$ is that the cross-derivative of the objective with respect to $c_{1}$ and $\lambda$ is positive. Let us first compute the derivative of the objective in (7) with respect to $\lambda$. We get

$$
\left[u_{2}^{\prime}\left(c_{2}\left(c_{1}, \lambda\right)\right)-\mu R u_{3}^{\prime}\left(w-R^{2} c_{1}-R c_{2}\left(c_{1}, \lambda\right)\right)\right] \frac{\partial c_{2}}{\partial \lambda}\left(c_{1}, \lambda\right) .
$$

By using (6), the bracketed term reduces to

$$
R(\lambda-\mu) u_{3}^{\prime}\left(w-R^{2} c_{1}-R c_{2}\left(c_{1}, \lambda\right)\right)
$$

Using (6) again, we obtain that

$$
\frac{\partial c_{2}}{\partial \lambda}\left(c_{1}, \lambda\right)=\frac{R u_{3}^{\prime}\left(w-R^{2} c_{1}-R c_{2}\left(c_{1}, \lambda\right)\right)}{u_{2}^{\prime \prime}\left(c_{2}\left(c_{1}, \lambda\right)\right)+\lambda R^{2} u_{3}^{\prime \prime}\left(w-R^{2} c_{1}-R c_{2}\left(c_{1}, \lambda\right)\right)} .
$$

Therefore the derivative of the objective in (7) with respect to $\lambda$ has the same sign as

$$
(\lambda-\mu)\left[\frac{u_{3}^{\prime 2}\left(w-R^{2} c_{1}-R c_{2}\left(c_{1}, \lambda\right)\right)}{u_{2}^{\prime \prime}\left(c_{2}\left(c_{1}, \lambda\right)\right)+\lambda R^{2} u_{3}^{\prime \prime}\left(w-R^{2} c_{1}-R c_{2}\left(c_{1}, \lambda\right)\right)}\right] \equiv(\lambda-\mu) X .
$$

Notice that $X$ is negative under risk aversion. Hence, as $\lambda$ moves away from $\mu$, the value for the objective function is reduced. The intuition for that observation is straightforward. Self-1 suffers from a loss in self-control, that is a radial increase in $\lambda$.

The problem reduces now to examining a single-crossing property, i.e. the sign of $(\lambda-\mu) \partial X / \partial c_{1}$. Suppose indeed that $\partial X / \partial c_{1}$ be positive, for any $\lambda$. Then the cross-derivative would have the sign of $\lambda-\mu$. Consequently the solution to program (7) would be decreasing with $\lambda$, then increasing, as depicted on Figure 1. In that case, it is clear that sophisticates consume 
more than naives, while the opposite would be true if $\partial X / \partial c_{1}$ was negative. Hence the sign of $\partial X / \partial c_{1}$ controls the comparative statics analysis. ${ }^{7}$

To sign this term, we need to introduce the following definitions used in the precautionary savings literature. For an increasing and concave function $u_{j}$, consider the following indexes:

$$
A_{j}(c)=-\frac{u_{j}^{\prime \prime}(c)}{u_{j}^{\prime}(c)} \quad P_{j}(c)=-\frac{u_{j}^{\prime \prime \prime}(c)}{u_{j}^{\prime \prime}(c)} .
$$

The first index is the well-known Arrow-Pratt's coefficient for absolute riskaversion. The second index is called the absolute prudence, and measures the propensity to increase savings when future income becomes riskier (Kimball, 1990).

We can now state our main result which is proven in the Appendix.

Proposition 1 The lack of self-control reduces (resp. increases) current savings for any $(w, R, \mu)$ if and only if both $u_{2}$ and $u_{3}$ verify the following condition:

$$
\forall c \quad P_{j}(c)-2 A_{j}(c) \geq 0(\text { resp. }<0), j=2,3 .
$$

Proposition 1 shows that the qualitative effect of a change in $\lambda$ is controlled by the second and third derivatives of the utility functions and does not depend on whether preferences are present-biased $(\lambda<\mu)$ or futurebiased $(\lambda>\mu)$. The proof makes it clear that this condition also ensures a

\footnotetext{
${ }^{7}$ Moreover, observe that $X$ does not depend on $\mu$. This indicates that the impact of self-control does not depend on whether preferences are present-biased or future-biased.
} 
monotonicity property: the proposition holds as well as $\lambda$ moves away from $\mu$. In other words, if prudence is lower than twice risk-aversion savings increase when the problem of self-control becomes more severe, while the opposite is true if the condition is reversed (see Figure 1 for an illustration). Our intuition for that result is the following.

INSERT FIGURE 1 ABOUT HERE.

First denote

$$
U\left(c_{1}, c_{2}, \mu\right)=u_{1}\left(c_{1}\right)+u_{2}\left(c_{2}\right)+\mu u_{3}\left(w-R^{2} c_{1}-R c_{2}\right),
$$

so that the sophisticate's objective is to maximize $U\left(c_{1}, c_{2}\left(c_{1}, \lambda\right), \mu\right)$ over $c_{1}$ where $c_{2}\left(c_{1}, \lambda\right)$ is given in (6). The first order condition simply gives

$$
\frac{\partial c_{2}}{\partial c_{1}}\left(c_{1}, \lambda\right)=-\frac{U_{1}}{U_{2}}\left(c_{1}, c_{2}\left(c_{1}, \lambda\right), \mu\right)
$$

where $U_{i}$ denote partial derivatives of $U{ }^{8}$

Note that the right-hand-side of the previous equation is simply the slope of indifference curves at $\left(c_{1}, c_{2}\left(c_{1}, \lambda\right)\right)$. On Figure 2, indifference curves are represented in the plane $\left(c_{1}, c_{2}\right)$ by ellipses around the optimal naive's consumption point $N$. For a given $\lambda$, the sophisticate's optimal consumption is then given by $S$, i.e. the point $\left(c_{1}, c_{2}\left(c_{1}, \lambda\right)\right)$ characterized by the tangency condition (9).

\footnotetext{
${ }^{8}$ Equation (9) is nothing else than the modified Euler equation (Harris and Laibson, $2001)$, i.e., $u_{1}^{\prime}\left(c_{1}\right)=R u_{3}^{\prime}\left(w-R^{2} c_{1}-R c_{2}\left(c_{1}, \lambda\right)\right)\left[(\mu-\lambda) \frac{\partial c_{2}}{\partial c_{1}}\left(c_{1}, \lambda\right)+\mu R\right]$.
} 
This graph makes it clear that the way $S$ reacts to a change in $\lambda$ is controlled by the change of the slope of the indifference curves $-U_{1} / U_{2}$ compared to the change of self-2's marginal propensity to consume $\partial c_{2} / \partial c_{1}$. The first effect on $-U_{1} / U_{2}$ indicates that when $\lambda$ changes the rate of marginal substitution between period 1 and period 2's consumption changes as well. This is only because any change in $\lambda$ changes the point $\left(c_{1}, c_{2}\left(c_{1}, \lambda\right)\right)$ at which this marginal rate of substitution $-U_{1} / U_{2}$ is computed. This effect thus captures how self-1's preferences over $\left(c_{1}, c_{2}, w-R^{2} c_{1}-R c_{2}\right)$ changes as $c_{2}$ changes. This effect is controlled by the second derivative of the utility functions.

\section{INSERT FIGURE 2 ABOUT HERE.}

Yet, there is a second effect, that is the effect on self-2's marginal propensity to consume. Indeed, when $\lambda$ changes, not only does $c_{2}$ change, but the way self-2 splits any unit of self-1's savings changes. This effect is controlled by both the second and the third derivatives of the utility functions. Proposition 1 thus gives the necessary and sufficient condition to compare these two effects, which actually depends on the coefficient of prudence compared to the coefficient of absolute risk aversion. Figure 2 actually represents a case where prudence is lower than twice absolute risk aversion so that period 1's consumption decreases with a radial increase in $\lambda$.

Proposition 1 thus provides a strong generalization of Pollack (1968)'s result. Indeed integrating the condition $P-2 A=0$ gives the logarithmic utility functions, $u(x)=\log x$. Thus among the class of all increasing and 
concave utility functions, the logarithmic utility function is the only one such that the naives and sophisticates' consumption levels coincide. More generally, within the Constant Relative Risk Aversion class of utility functions, we have $P \geq 2 A$ if and only if the relative risk aversion parameter is below 1. This level for relative risk aversion is generally recognized as low for households. ${ }^{9}$

Note also that the condition $P \geq 2 A$ is stronger than the condition of Decreasing Absolute Risk Aversion (DARA), which is actually equivalent to $P \geq A$. Debreu and Koopmans (1982) argue that a mathematical measure of risk aversion is the following "concavity index" $\frac{-u^{\prime \prime}}{\left(u^{\prime}\right)^{2}}$. It turns out that with the Debreu and Koopmans' index, decreasing absolute risk aversion reduces to $P \geq 2 A$. In this case only, undersaving may be viewed as a natural consequence of time-inconsistency.

Finally, an interesting implication of the condition on the utility function derived in Proposition 1 is that it makes immediate the generalization of the comparative statics to conditions of uncertainty. Suppose indeed that future revenues are unknown, $\widetilde{w} \equiv w+\widetilde{\varepsilon}$. Let define the indirect utility function

$$
v(x)=E u_{3}(x+\widetilde{\varepsilon}),
$$

and denote respectively $P_{v}$ and $A_{v}$ for absolute prudence and absolute risk

\footnotetext{
${ }^{9}$ Recently, it has been shown that the sign of $P-2 A$ controls the comparative statics of many decision problems under uncertainty. For example, in finance, Gollier (2001) proved that the sign of $P-2 A$ determines whether independent risky assets are substitutes or complements (Proposition 36) or whether opening new risky investment opportunities raises or reduces aggregate savings (Propositions 74 and 75). Alesina and Tabellini (1990) obtained the same condition to characterize the budget deficit policy under uncertainty.
} 
aversion of $v$. The point is that Carroll and Kimball (1996, Lemma 1) showed that

$$
P_{3} \geq 2 A_{3} \text { implies } P_{v} \geq 2 A_{v} .
$$

As a result, our condition is left unchanged when there is some uncertainty on future revenues.

\section{Generalized Preferences}

Until now, we have investigated the effect of self-control into the simple canonical consumption model. This analysis has required the examination of the sophisticate's problem. Technically, we have thus studied the sensitivity of a Stackelberg equilibrium to changes in a discount factor from $\mu$ to $\lambda$. It seems reasonable to think that this analysis has been made possible only due to the strong regularity properties of the pure consumption model. In this section, we show that the analysis extends to a broader class of models.

Consider the family of models taking the form of

$$
\max _{c_{1}, c_{2}} U\left(c_{1}, c_{2}, \mu\right)
$$

where $c_{1}$ and $c_{2}$ are respectively the first and second period decisions. ${ }^{10}$ Assume that the objective is concave in $c_{2}$ and twice differentiable in $c_{1}$ and $c_{2}$. Here $\mu$ is interpreted as a discount factor, so $U$ is assumed to be linear in $\mu$. As before, we consider a change in future preferences from $\mu$ to $\lambda$, so that

\footnotetext{
${ }^{10}$ This simply generalizes the previous model as written in (8).
} 
$c_{2}\left(c_{1}, \lambda\right)$ is characterized by

$$
U_{2}\left(c_{1}, c_{2}\left(c_{1}, \lambda\right), \lambda\right)=0
$$

Now denote

$$
H\left(c_{1}, \lambda, \mu\right)=U\left(c_{1}, c_{2}\left(c_{1}, \lambda\right), \mu\right)
$$

for the objective to be maximized in the first period by the sophisticate. Using this general notation, one can easily see that any change in parameter $\lambda$ changes the current objective $H\left(c_{1}, \lambda, \mu\right)$ only indirectly, i.e. only through the effect it has on the future decision. In other words, the effect of selfcontrol can be properly investigated since a change in $\lambda$ does not affect current preferences. Note that from (10) we have

$$
H_{\lambda}\left(c_{1}, \lambda, \lambda\right)=0
$$

Now define the naive's objective as

$$
V\left(c_{1}, \mu\right)=H\left(c_{1}, \mu, \mu\right) .
$$

The problem of comparing the first period decisions for naives and sophisticates reduces now to comparing $H_{1}\left(c_{1}, \lambda, \mu\right)$ with $V_{1}\left(c_{1}, \mu\right)$. We show in appendix the following result:

Proposition 2 Assume that $U\left(c_{1}, c_{2}, \mu\right)$ is linear in $\mu$. Define the value function

$$
V\left(c_{1}, \mu\right)=\max _{c_{2}} U\left(c_{1}, c_{2}, \mu\right)
$$

The lack of self-control reduces $c_{1}$ if and only if $V_{1}\left(c_{1}, \mu\right)$ is concave in $\mu$. 
This proposition shows that the impact of self-control may be analyzed without solving for the sophisticate's problem. Only the naive's problem has to be examined, so that standard tools of dynamic decision theory, such as the Envelope Theorem, may be used to investigate the comparative statics of self-control. ${ }^{11}$

Now let us generalize the model to assume that there is uncertainty over the future discount factor $\mu$. Note that the marginal value of increasing $c_{1}$ under uncertainty is given by

$$
E V_{1}\left(c_{1}, \mu\right)
$$

which under concavity of $V_{1}$ is less than the marginal value of increasing $c_{1}$ when $\mu$ is known to take its mean value $E \mu$,

$$
V_{1}\left(c_{1}, E \mu\right)
$$

Hence the concavity of $V_{1}\left(c_{1}, \mu\right)$ in $\mu$ also controls the effect of uncertainty on $\mu$ on $c_{1}$. We have thus shown that the condition on preferences that is necessary and sufficient for $c_{1}$ to decrease when a self-control problem is introduced is also necessary and sufficient for $c_{1}$ to increase when uncertainty on the discount factor $\mu$ is introduced. This helps to understand the appearance of the coefficient of prudence as a key quantity to sign the comparative statics analysis of self-control in a consumption model. We suggest that this

\footnotetext{
${ }^{11}$ In particular, when $V\left(c_{1}, \mu\right)=\max _{c_{2}} u\left(c_{2}\right)+\mu u\left(w-R^{2} c_{1}-R c_{2}\right)$ then $-V_{1 \mu \mu}$ has the sign of $P-2 A$. This illustrates how Proposition 2 extends Proposition 1.
} 
formal homology is due to the existence of two opposite effects identified in the precautionary savings literature (Drèze and Modigliani, 1972). These two effects may be briefly presented as follows. ${ }^{12}$

Under uncertainty on $\mu$, the optimal response in period 2 is $c_{2}\left(c_{1}, \mu\right)$. Suppose now that the second period decision does not respond to uncertainty, i.e. the decision is $c_{2}\left(c_{1}, E \mu\right)$. Anticipating this future decision rule has two effects on the first-period decision $c_{1}$. First, since the future decision is sub-optimal, this effect is similar to a decrease in future revenues and it increases in general the willingness to save under risk aversion. This is an income effect. But another effect takes place, more in line with a substitution effect, or, say, a precautionary savings effect. Any unit of savings which is split according to the decision rule $c_{2}\left(c_{1}, E \mu\right)$ reduces the variability of future revenues since it is insensitive to $\mu$. This effect thus reduces in general the precautionary savings motive under prudence.

Our analysis thus suggests that discount factors uncertainty is a candidate to explain the observed low rate of savings by some households. ${ }^{13}$ The following simple example illustrates this point. Consider our consumption model

\footnotetext{
${ }^{12}$ Related interpretations may be found in Epstein (1980) and Gollier, Jullien and Treich (2000).

${ }^{13}$ A similar hypothesis is introduced by Sozou (1998) and Dasgupta and Maskin (2002) to show how hyperbolic discounting may emerge due to uncertainty over discounting. There exist two main differences with our analysis though: first, these two papers consider uncertainty over discount rates, not discount factors. Second, they do not allow for uncertainty resolution over time while in our model the agent learns the value of $\mu$ at period 2 .
} 
as presented in Section 2 and assume $\mu=R=w=1$ and $u_{1}=u_{2}=u_{3}=u$ with $u(c)=-(1-c)^{2}$. Perfect smoothing is optimal: the agent consumes $1 / 3$ in period 1. Suppose, however, that one observes over-consumption today. Then self-control problems cannot explain this observation. Indeed period 1 consumption equals $\lambda /\left(1+\lambda+\lambda^{2}\right)$ which is always lower than $1 / 3$ (this is because for this quadratic utility function we have $P=0<2 A$ ). An alternative explanation would be to introduce uncertainty over future discount factors, e.g., $\mu^{+}=1+\varepsilon$ or $\mu^{-}=1-\varepsilon$ with equal probability. Then period 1 consumption equals $1 /\left(3-\varepsilon^{2}\right)$, which is indeed larger than $1 / 3$, and thus may explain the observed over-consumption. Similar effects would arise with the more traditional iso-elastic function $u(c)=c^{1-\gamma} /(1-\gamma)$, when $\gamma$ is above one.

To sum up, our analysis has shown that the relation between undersavings and self-control problems is less clear than previously hypothesized by economists. In particular, this relation critically depends on the consumer's utility function. Besides, our analysis has introduced a new hypothesis to explain undersavings. Indeed, we have shown that savings decrease in response to uncertainty over future discount factors, and the critical condition on the utility function for this effect to hold is the same as the one to sign the effect of self-control. Our analysis thus ends up with the question of whether a more general time-consistent framework could not better explain some empirical anomalies than the time-inconsistent framework. 


\section{Conclusion}

In his Alfred Marshall's lecture, Matthew Rabin indicated that "psychologically inspired models that allow the possibility of less-than-100\% self control (...) allow us to investigate the possibility that people under-save" (Rabin, 2002, p. 659). In this paper, we have tried to investigate this possibility, namely to establish a connection between the absence of self-control and undersavings in a model with non-exponential discounting.

We have shown that this connection is true only if the agent is prudent enough. Intuitively, two effects enter in the picture. First, less self-control reduces the incentives to save since any unit of savings will be sub-optimally allocated in the future. Under prudence, this effect is similar to the effect of less uncertainty on future discount factors. However, since the future consumption decision is sub-optimal, the effect of a loss of self-control is also comparable to a reduction in future revenues. This, in turn, increases the willingness to save. Under usual assumptions on preferences, this last effect dominates, so that the lack of self-control could well lead to over-savings. 


\section{Appendix}

Proof of Proposition 1: We want to examine the sign of

$$
\partial X / \partial c_{1}=\frac{\partial}{\partial c_{1}}\left[\frac{u_{3}^{\prime 2}\left(w-R^{2} c_{1}-R c_{2}\left(c_{1}, \lambda\right)\right)}{u_{2}^{\prime \prime}\left(c_{2}\left(c_{1}, \lambda\right)\right)+\lambda R^{2} u_{3}^{\prime \prime}\left(w-R^{2} c_{1}-R c_{2}\left(c_{1}, \lambda\right)\right)}\right] .
$$

Using obvious notations, $\partial X / \partial c_{1}$ has the sign of

$$
-2 u_{3}^{\prime \prime}\left(R^{2}+R \frac{\partial c_{2}}{\partial c_{1}}\right)\left(u_{2}^{\prime \prime}+\lambda R^{2} u_{3}^{\prime \prime}\right)-u_{3}^{\prime}\left(u_{2}^{\prime \prime \prime} \frac{\partial c_{2}}{\partial c_{1}}-\lambda R^{2} u_{3}^{\prime \prime \prime}\left(R^{2}+R \frac{\partial c_{2}}{\partial c_{1}}\right)\right) .
$$

$>$ From (6), we use

$$
\frac{\partial c_{2}}{\partial c_{1}}=\frac{-\lambda R^{3} u_{3}^{\prime \prime}}{u_{2}^{\prime \prime}+\lambda R^{2} u_{3}^{\prime \prime}}
$$

so that multiplying by $-\left(u_{2}^{\prime \prime}+\lambda R^{2} u_{3}^{\prime \prime}\right)>0$, we get

$$
2 u_{2}^{\prime \prime} u_{3}^{\prime \prime}\left(u_{2}^{\prime \prime}+\lambda R^{2} u_{3}^{\prime \prime}\right)-u_{3}^{\prime}\left(\lambda R u_{2}^{\prime \prime \prime} u_{3}^{\prime \prime}+\lambda R^{2} u_{3}^{\prime \prime \prime} u_{2}^{\prime \prime}\right)
$$

Dividing by $u_{2}^{\prime \prime} u_{3}^{\prime \prime} u_{3}^{\prime}>0$ yields

$$
2\left(u_{2}^{\prime \prime} / u_{3}^{\prime}+\lambda R^{2} u_{3}^{\prime \prime} / u_{3}^{\prime}\right)-\lambda R\left(u_{2}^{\prime \prime \prime} / u_{2}^{\prime \prime}+R u_{3}^{\prime \prime \prime} / u_{3}^{\prime \prime}\right) .
$$

Using again $u_{2}^{\prime}=\lambda R u_{3}^{\prime}$ gives

$$
\frac{-u_{2}^{\prime \prime \prime}}{u_{2}^{\prime \prime}}+R \frac{-u_{3}^{\prime \prime \prime}}{u_{3}^{\prime \prime}}-2\left(\frac{-u_{2}^{\prime \prime}}{u_{2}^{\prime}}+R \frac{-u_{3}^{\prime \prime}}{u_{3}^{\prime}}\right)
$$

so that, $\partial X / \partial c_{1}$ has the same sign as

$$
P_{2}\left(c_{2}\right)-2 A_{2}\left(c_{2}\right)+R\left[P_{3}\left(c_{3}\right)-2 A_{3}\left(c_{3}\right)\right]
$$

Therefore the conditions given in the Proposition are sufficient to sign the change in current consumption due to a change in $\lambda$, as explained in the text. 
Let us now turn to the necessity part. Suppose that at some $\left(c_{2}, c_{3}\right)$, at least one of the two conditions

$$
P_{2}\left(c_{2}\right) \geq 2 A_{2}\left(c_{2}\right) \quad P_{3}\left(c_{3}\right) \geq 2 A_{3}\left(c_{3}\right)
$$

does not hold. Then for $R>0$ well-chosen, (12) is negative, and therefore $\partial X / \partial c_{1}<0$. Now choose $\left(c_{1}, w, \mu\right)$ to verify the two optimality conditions (5) and the budget constraint. Then $\left(c_{1}, c_{2}, c_{3}\right)$ is the unique solution to the naive's program, which is strictly concave. By a continuity argument, there exists a $\lambda$ (close enough to $\mu$ ) for which the sophisticate program (7) is also strictly concave, and admits a unique solution. Since the cross-derivative has the sign of $(\lambda-\mu) \partial X / \partial c_{1}$, and $\partial X / \partial c_{1}$ has just been shown to be negative, we get that the solution to the sophisticate program increases, then decreases with $\lambda$. We thus have obtained a contradiction.

Proof of Proposition 2: We want to compare the functions $H_{1}\left(c_{1}, \lambda, \mu\right)$ and $V_{1}\left(c_{1}, \mu\right)$. These functions share the same slope with respect to $\mu$ at $\mu=\lambda$. Indeed we have from (11)

$$
V_{\mu}\left(c_{1}, \lambda\right)=H_{\mu}\left(c_{1}, \lambda, \lambda\right)
$$

so that

$$
V_{1 \mu}\left(c_{1}, \lambda\right)=H_{1 \mu}\left(c_{1}, \lambda, \lambda\right)
$$

Hence, since the slopes are the same at $\mu=\lambda$ and since $H_{1}\left(c_{1}, \lambda, \mu\right)$ is linear in $\mu$, it is immediate that we are done if we are able to sign the convexity 
of $V_{1}\left(c_{1}, \mu\right)$ in $\mu$. For instance if $V_{1}\left(c_{1}, \mu\right)$ is convex in $\mu$, then $V_{1}\left(c_{1}, \mu\right)$ is above $H_{1}\left(c_{1}, \lambda, \mu\right)$, and the naive chooses a higher $c_{1}$ than the sophisticate. Note that the convexity of $V_{1}\left(c_{1}, \mu\right)$ provides also a necessary condition since around $\mu=\lambda, V_{1}\left(c_{1}, \mu\right)$ is above $H_{1}\left(c_{1}, \lambda, \mu\right)$ only if it is convex in $\mu$. 


\section{References}

Alesina A., and G. Tabellini, 1990, Voting on budget deficit, American Economic Review 80, 37-49.

Angeletos, G.-M., Laibson D., Repetto A., Tobacman, J. and S. Weinberg, 2001, The hyperbolic buffer stock model: Calibration, simulation and empirical evaluation, Journal of Economic Perspectives 15, 47-68.

Barro, R.J., 1999, Ramsey meets Laibson in the neoclassical growth model, Quarterly Journal of Economics 114, 1125-52.

Caroll, C.D. and M. Kimball, 1996, On the concavity of the consumption function, Econometrica 64, 981-92.

Dasgupta P. and E. Maskin, 2002, Uncertainty, waiting costs, and hyperbolic discounting, mimeo, Princeton University.

Debreu, G. and T.C. Koopmans, 1982, Additively decomposed quasiconvex functions, Mathematical Programming 24, 1-38.

Diamond, P. and B. Koszegi, 2003, Quasi-hyperbolic discounting and retirement, Journal of Public Economics 87, 1839-72.

Drèze, J. and F. Modigliani, 1972, Consumption decisions under uncertainty, Journal of Economic Theory 5, 308-35.

Epstein, L.S., 1980, Decision-making and the temporal resolution of uncertainty, International Economic Review 21, 245-64.

Goldman, S.M., 1979, Intertemporally inconsistent preferences and the 
rate of consumption, Econometrica 47, 621-26.

Goldman, S.M., 1980, Consistent plans, Review of Economic Studies 47, $533-37$.

Gollier, C., 2001, The Economics of Risk and Time, MIT Press, Cambridge.

Gollier, C., Jullien B., and Treich N., 2000, Scientific progress and irreversibility: An economic interpretation of the Precautionary Principle, Journal of Public Economics 75, 229-53.

Gul, F. and W. Pesendorfer, 2001, Temptation and self-control, Econometrica 69, 1403-35.

Gul, F. and W. Pesendorfer, 2002, Self-control, revealed preference and consumption choice, Review of Economic Dynamics, forthcoming.

Gul, F. and W. Pesendorfer, 2004, Self-control and the theory of consumption, Econometrica 72, 119-58.

Harris, C. and D. Laibson, 2001, Dynamic choices of hyperbolic consumers, Econometrica 69, 235-58.

Kimball, M., 1990, Precautionary saving in the small and in the large, Econometrica 58, 53-73.

Laibson, D., 1997, Golden eggs and hyperbolic discounting, Quarterly Jounal of Economics 62, 443-77.

Laibson, D., 1998, Life-Cycle Consumption and hyperbolic discount functions, European Economic Review 42, 861-71.

Milgrom, P. and C. Shannon, 1994, Monotone comparative statics, Econo- 
metrica $62,157-80$.

O'Donoghue, T. and M. Rabin, 1999a, Doing it now or later, American Economic Review 89, 103-25.

O’Donoghue, T. and M. Rabin, 1999b, Incentives for procrastinators, Quarterly Journal of Economics 64, 769-816.

Phelps, E.S. and R.A. Pollack, 1968, On second-best national savings and game-equilibrium growth, Review of Economic Studies 35, 185-99.

Pollack, R.A., 1968, Consistent planning, Review of Economic Studies 35, 201-08.

Rabin, M., 2002, A perspective on psychology and economics, European Economic Review 46, 657-85.

Sozou, P.D., 1998, On hyperbolic discounting and uncertain hazard rates, Proceedings of the Royal Society of London (series B) 265, 2015-2020.

Strotz R., 1956, Myopia and inconsistency in dynamic utility maximization, Review of Economic Studies 23, 165-80. 


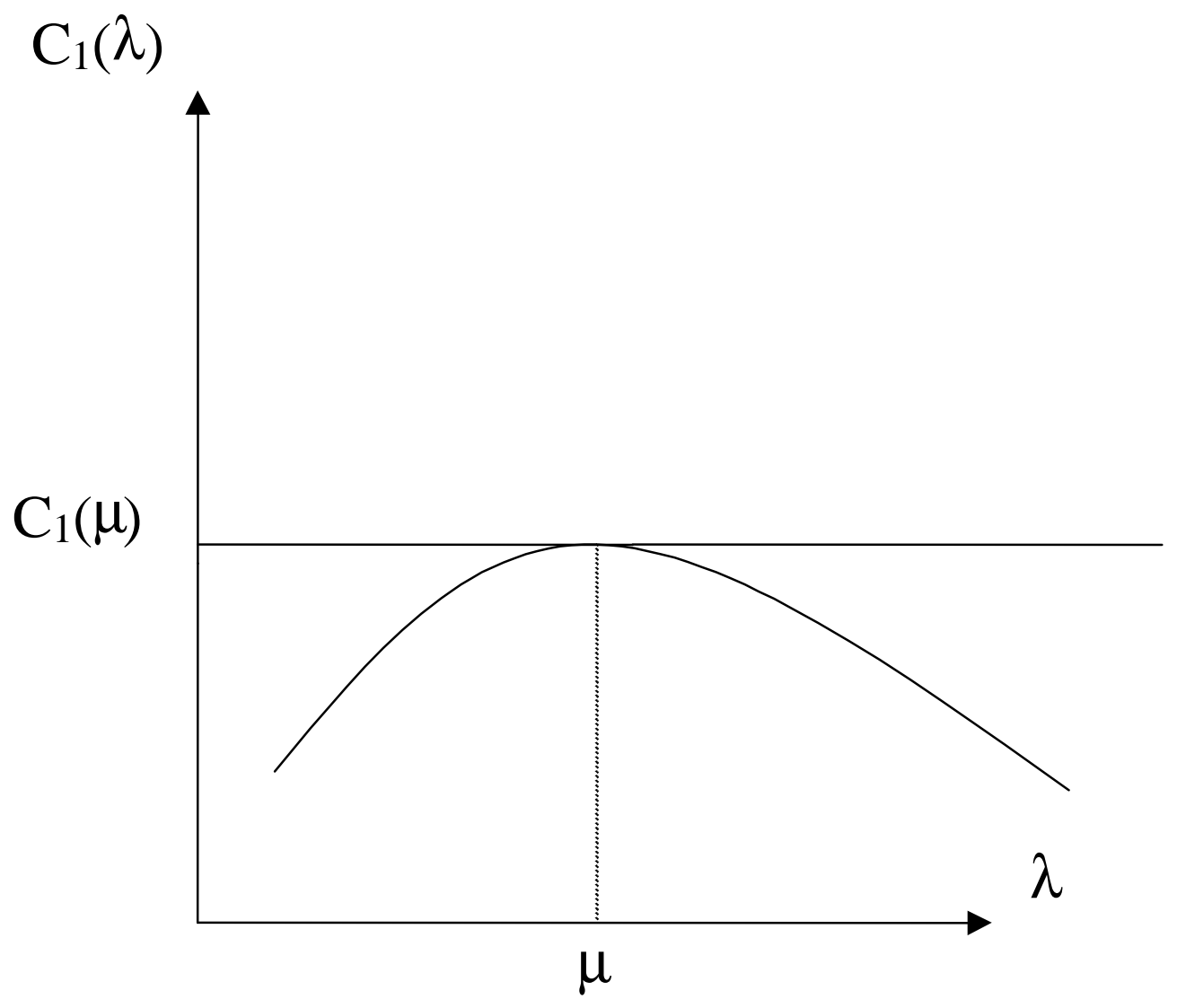

Figure 1:

Period 1 consumption as a function of the discount factor $\lambda$. Consumption decreases with more self-control problem, that is with a radial increase of $\lambda$. 


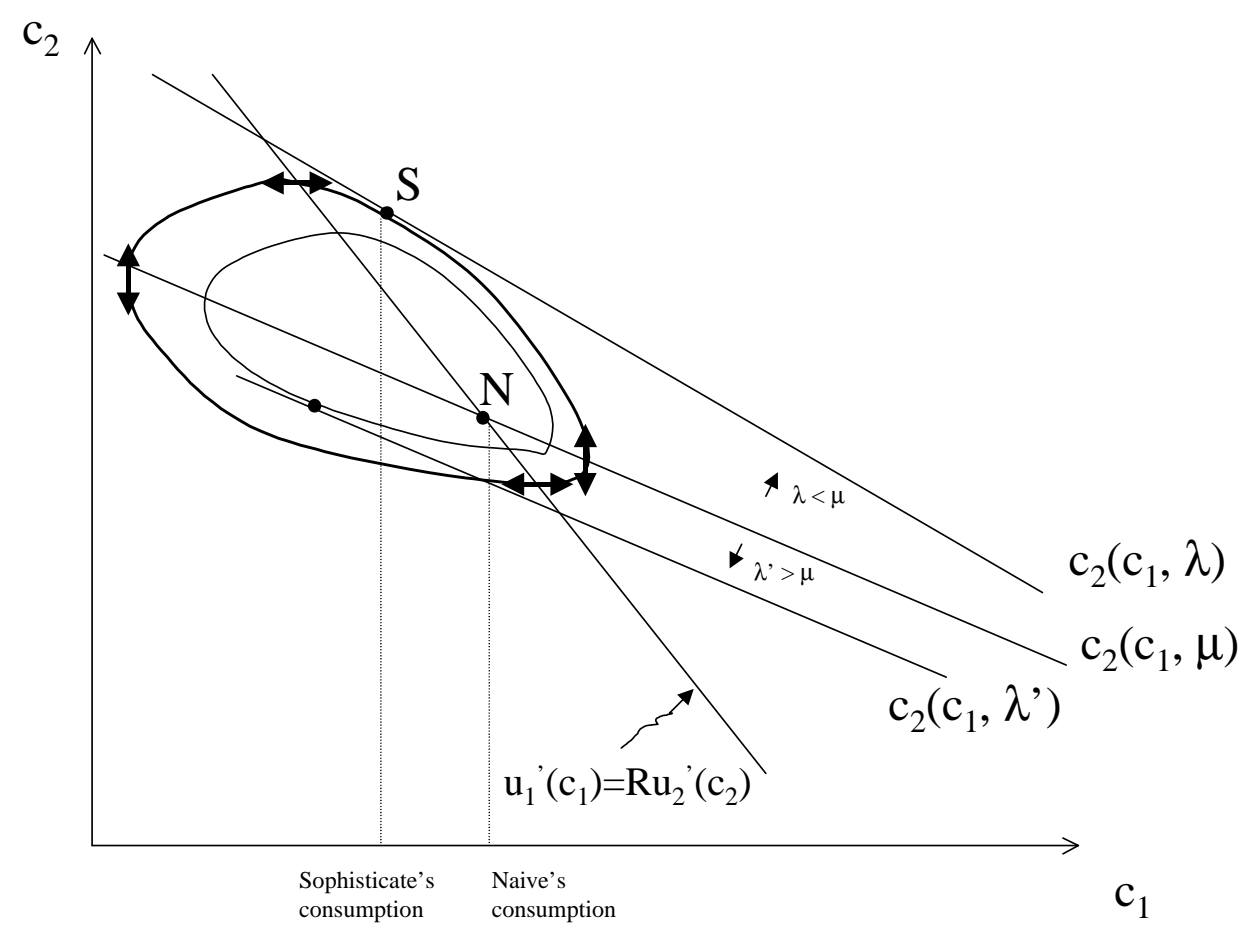

Figure 2:

$\mathrm{N}$ characterizes the naive's optimal consumption, i.e. the two Euler conditions (5). S characterizes the sophisticate's optimal consumption, i.e. conditions (9). Ellipses represent indifference curves of preferences (8). This Figure sets a situation where the coefficient of prudence is lower than twice the coefficient of absolute risk aversion, so that consumption decreases with a radial increase of $\lambda$. 